\author{
Renata Cristina Silva Baldo ${ }^{1}$ \\ Regina Stella Spagnuolo ${ }^{2}$
}

Ildeberto Muniz de Almeida ${ }^{3}$

\section{O Serviço Integrado de Atendimento ao Trauma em Emergência (SIATE) como fonte de informações de acidentes de trabalho em Londrina, PR}

\author{
The Emergency Trauma Care Integrated Service (SIATE) \\ as a source of information on occupational accidents in \\ Londrina, PR, Brazil
}

${ }^{1}$ Secretaria Municipal de Saúde de Londrina, Vigilância Epidemiológica, Núcleo de Atenção à Saúde do Trabalhador. Londrina, PR, Brasil.

${ }^{2}$ Universidade Estadual Paulista "Júlio de Mesquita Filho", Faculdade de Medicina de Botucatu, Departamento de Enfermagem. Botucatu, SP, Brasil.

${ }^{3}$ Universidade Estadual Paulista "Júlio de Mesquita Filho", Faculdade de Medicina de Botucatu, Departamento de Saúde Pública. Botucatu, SP, Brasil.

Contato:

Renata Cristina Silva Baldo

E-mail:

renatabaldo@sercomtel.com.br

Trabalho baseado em dissertação de mestrado de Renata Cristina Silva Baldo, sob o título "Acidentes de trabalho atendidos pelo Serviço Integrado de Atendimento ao Trauma em Emergências, Londrina, PR", defendida em 2010 na Faculdade de Medicina de Botucatu/UNESP.

Resultados parciais apresentados no $12^{\circ}$ EXPOEPI, em exposição oral (na categoria mestrado). Evento realizado em outubro de 2012 na cidade de Brasília, DF, tendo seu resumo publicado nos anais do evento.

Os autores declaram não haver conflitos de interesses e que o trabalho não foi subvencionado.

\section{Resumo}

Objetivo: descrever as características dos acidentes de trabalho e o perfil das vítimas atendidas pelo Serviço Integrado de Atendimento ao Trauma em Emergência, de Londrina (SIATE), PR. Métodos: trata-se de estudo descritivo transversal. Os dados foram coletados no período de $1^{\circ}$ julho a 31 de dezembro de 2008, por meio de entrevistas telefônicas às vítimas ou familiares e busca de informações complementares em relatórios de atendimento dos socorristas. Resultados: foram realizadas 1.312 entrevistas, sendo $465(35,4 \%)$ casos considerados acidentes de trabalho. O perfil predominante dos acidentados é jovem, do sexo masculino, inserido no mercado formal de trabalho como empregado. A maioria dos acidentes de trabalho ocorreu na rua, sendo 376 (80,9\%) relacionados ao trânsito; desses, cerca de $65,0 \%$ foram identificados como acidentes de trajeto. Nenhum dos casos foi notificado em sistema de informação do Ministério da Saúde. Junto à Previdência Social houve subnotificação de cerca de $40 \%$ dos casos de acidentes ocorridos com trabalhadores formais. Conclusão: os serviços de Saúde do Trabalhador devem priorizar ações de prevenção de acidentes ocorridos no espaço da rua, assim como implantar rotinas sistematizadas a fim de intensificar a notificação dos casos em bancos de dados de interesse nacional, conforme preconiza o Ministério da Saúde.

Palavras-chave: acidentes de trabalho; saúde do trabalhador; acidentes de trânsito; acidentes de trajeto; subnotificação.

\begin{abstract}
Objective: to describe the occupational accidents characteristics and the profile of their victims assisted by the Emergency Trauma Care Integrated Service (SIATE) in Londrina, PR, Brazil. Methods: a descriptive cross-sectional study; data was collected from July $1^{\text {st }}$ to December $31^{\text {st }}$, 2008, through telephone interviews with the victims or their relatives. Additional information was collected from SIATE rescuers' reports. Results: 1,312 interviews were performed and 465 (35.4\%) cases were considered occupational accidents. The predominant profile of such victims was of a young male legally employed. Most occupational accidents occurred in the street, and $376(80.9 \%)$ were traffic-related. Of those, approximately $65.0 \%$ were identified as occupational route accidents. None of the identified cases had been reported to the Ministry of Health Information System. The Social Security system shows 40.0\% underreporting involving formal workers accidents. Conclusion: occupational health services should prioritize prevention actions on accidents occurred in the streets, as well as implement systematic routines aiming at enhancing the reporting of these cases in databases of national interest, in accordance with the Ministry of Health.
\end{abstract}

Keywords: occupational accidents; workers' health; traffic accidents; route accidents; underreporting. 


\section{Introdução}

A partir dos anos 1980, um dos pontos mais relevantes da transição epidemiológica no Brasil foi a expressiva elevação da morbimortalidade por causas externas, compreendida como um conjunto de agravos não naturais, em que são despendidos anualmente bilhões de dólares em assistência à saúde em todo o mundo, além de aumentar os afastamentos do trabalho, diminuir a produtividade e, ainda, destinar recursos com aplicação das leis (ORGANIZAÇÃO MUNDIAL DE SAÚDE, 2002; GAWRYSZEWSKI; KOIZUMI; MELLO JORGE, 2004; MELLO JORGE; KOIZUMI, 2004).

Nesse sentido, há necessidade de se compreender que parte desses agravos por causas externas está ligada ao processo de trabalho de grande parcela da população.

Segundo o Protocolo de Complexidade Diferenciada de Notificação de Acidentes do Trabalho Fatais, Graves e com Crianças e Adolescentes do Ministério da Saúde, acidente de trabalho (AT) é:

O evento súbito ocorrido no exercício de atividade laboral, independentemente da situação empregatícia e previdenciária do trabalhador acidentado, e que acarreta dano à saúde, potencial ou imediato, provocando lesão corporal ou perturbação funcional que causa, direta ou indiretamente (concausa), a morte, ou a perda ou redução, permanente ou temporária, da capacidade para o trabalho. Inclui-se ainda o acidente ocorrido em qualquer situação em que o trabalhador esteja representando os interesses da empresa ou agindo em defesa de seu patrimônio; assim como aquele ocorrido no trajeto da residência para o trabalho e vice-versa. (BRASIL, 2006, p. 11)

O uso dessa definição em serviços de saúde permite revelar AT que acometam vítimas independentemente do vínculo empregatício.

O Brasil é um dos recordistas mundiais de AT, com três mortes a cada duas horas e três eventos não fatais a cada minuto (FACCHINI et al., 2005). Durante o ano de 2013 foram registrados cerca de 718 mil AT (BRASIL, 2013). No estado do Paraná, para o ano de 2013, o número de registros foi de 52.132, sendo que 4.078 desses ocorreram no município de Londrina (BRASIL, 2015). No entanto, há fortes indícios de que a incidência de AT oficialmente notificados no Brasil esteja gravemente subdimensionada (FACCHINI et al., 2005; MEDEIROS et al., 2005).

A notificação dos AT no Brasil se dá por meio de dois sistemas de informação independentes. O primeiro é a Comunicação de Acidente de Trabalho (CAT) do Ministério da Previdência Social (MPS), com finalidade previdenciária, que se limita apenas a parcela da população de trabalhadores com carteira assinada, regidos pela Consolidação das Leis Trabalhistas (CLT) e cobertos pelo Seguro Acidente de Trabalho (SAT). O segundo é o Sistema de Informação de Agravos de Notificação (SINAN) do Sistema Único de Saúde (SUS), instituído pela Portaria n. 777/2004, que foi substituída pela Portaria 104/2011 e posteriormente pela Portaria n. 1.271/2014 (BRASIL, 2005a, 2011, 2014). A portaria dispõe sobre a obrigatoriedade da notificação dos acidentes de trabalho fatais, graves e com crianças e adolescentes, independentemente do vínculo empregatício da vítima, com a finalidade de intervenção na prevenção de novos agravos relacionados ao trabalho. Dessa forma, O SUS busca revelar a magnitude do problema dos AT que os números oficiais da Previdência não revelam.

Em Londrina (PR), a maioria dos acidentes ocorridos, sobretudo os mais graves, são atendidos pelo Serviço Integrado de Atendimento ao Trauma em Emergência (SIATE), um serviço de atendimento pré-hospitalar. O atendimento pré-hospitalar é uma área de atuação da saúde que vem recebendo atenção diferenciada em nosso meio na última década. Tem como fundamento proporcionar a detecção rápida de situações de risco à vida ou função, a intervenção precoce iniciada a partir do local de ocorrência e o encaminhamento direto ao serviço de saúde, com resolução adequada para o caso. Essa atuação pode diminuir significativamente as sequelas e mortes resultantes dos agravos.

Portanto, considerando a importância de se reconhecer o trabalhador que se acidenta, independentemente do seu vínculo empregatício, a questão problematizadora deste estudo foi "qual a característica dos AT atendidos pelo serviço de atendimento ao trauma no município de Londrina, PR?".

Dessa forma, este estudo tem como objetivo descrever características dos AT e o perfil das vítimas atendidas em serviço integrado de atendimento ao trauma em emergência.

Em face desse cenário, justifica-se o estudo na medida em que são necessárias informações sobre as circunstâncias dos acidentes causadores de lesões nos trabalhadores, a fim de subsidiar o planejamento de ações preventivas, bem como implementar sistemas de informação existentes no SUS.

\section{Métodos}

Estudo descritivo transversal que busca identificar as vítimas de AT atendidas pelo SIATE no município de Londrina, PR.

A população amostral é composta por vítimas na faixa etária de 10 a 65 anos (população economicamente ativa), encaminhadas aos quatro hospitais selecionados 
para o estudo, sendo três de nível terciário e um de nível secundário (INSTITUTO BRASILEIRO DE GEOGRAFIA E ESTATÍSTICA, 2014). São hospitais conveniados ao SUS que recebem casos de acidentes de maior gravidade encaminhados pelo SIATE. Sendo assim, optou-se por excluir um hospital conveniado ao SUS que recebia casos de menor gravidade, assim como os Prontos Atendimentos. Relatórios on-line contendo data de atendimento, nome e telefone das vítimas foram encaminhados mensalmente à pesquisadora.

A coleta de dados se deu no período de $1^{\circ}$ de julho a 31 de dezembro de 2008 e ocorreu em dois momentos. Primeiro, por meio de ligação telefônica e, após consentimento verbal da vítima ou de familiar, utilizou-se entrevista aberta com a seguinte questão norteadora "o que o(a) Sr.(a) estava fazendo no momento em que ocorreu o acidente?" Essa etapa teve por finalidade identificar se o acidente ocorrera em situação relacionada ao trabalho, inclusive em situação de deslocamentos de ida e vinda a serviço ou para domicílio, trabalho ou local de refeição, independentemente da existência de vínculo empregatício.

Mediante resposta afirmativa para a ocorrência de AT, foi aplicado um questionário estruturado, contendo questões sobre inserção no mercado de trabalho, ocupação, circunstância do acidente, se típico ou de trajeto e conhecimento da emissão da CAT.

Para os agravos ocorridos em menores de idade, o consentimento foi fornecido por seu representante legal, que também respondeu à entrevista.

Foram considerados como perdas casos em que: a) não foi possível contato devido à inexistência do número do telefone nos relatórios hospitalares ou a número errado; b) as vítimas se recusaram a participar; c) as vítimas não foram encontradas após três tentativas de contato telefônico, utilizando-se o critério de, após ligação não atendida na primeira chamada, realizar mais duas em horários diferenciados, considerando-se os períodos da manhã, tarde e noite, sendo pelo menos uma em final de semana.

Num segundo momento, foram colhidas informações em Relatórios de Atendimento dos Socorristas (RAS), sendo as variáveis de interesse: tipo de ocorrência e presença de fratura transcrita para instrumento próprio, além de informações referentes ao sexo e idade. O RAS é preenchido em todos os atendimentos realizados pelo socorrista, independentemente da gravidade da lesão ou encaminhamento dado ao caso.

Foram excluídas desse estudo as 76 mortes constatadas pelo SIATE no momento do atendimento e encaminhadas diretamente ao Instituto Médico Legal (IML).

Os dados foram tabulados e analisados utilizando-se o programa Epi-Info versão 3.3, de domínio público (CENTERS FOR DISEASE CONTROL AND PREVENTION, 2005). Associação das variáveis gerou tabelas das características das vítimas e dos acidentes e das características específicas dos acidentes envolvendo motocicletas, por meio de frequências simples e relativa dos achados deste estudo.

A pesquisa foi aprovada pelo comitê de Bioética e Ética em Pesquisa da Irmandade da Santa Casa de Londrina sob o n. CEP 297/08 - CAEE: 0008.0.083.000-08. Ofício n. 014/08 BIOISCAL. Respeitaram-se todas as normas da Resolução 196/96 do Conselho Nacional de Saúde.

\section{Resultados}

O SIATE encaminhou aos quatro hospitais envolvidos, no período de $1^{\circ}$ de julho a 31 de dezembro de 2008, 2.894 vítimas. Em 1.312 (45,3\%) desses casos houve contato telefônico com vítimas ou familiares. Entre os demais casos, 1.403 (48,5\%) foram perdidos devido à impossibilidade de acesso a informações que permitissem o contato e 179 foram excluídos devido à idade da vítima ser inferior a 10 ou superior a 64 anos.

A distribuição dos casos em que foi possível contato telefônico mostra que 806 (61,4\%) foram considerados acidentes não relacionados ao trabalho, 494 (37,7\%) classificados como AT e 12 (0,9\%) recusas de resposta à questão.

Dos 494 casos considerados como AT, 29 casos foram perdidos por não terem sido encontrados os respectivos RAS durante busca no SIATE. Logo, este estudo descreve os 465 (35,4\%) acidentes que, segundo informações das vítimas ou familiares, tiveram relação com o trabalho.

As características das vítimas dos AT atendidas pelo SIATE são mostradas na Tabela 1.

Em relação a sexo e idade, o estudo mostra que as vítimas são, sobretudo, jovens do sexo masculino (78,1\%), com idade de 18 a 24 anos (32,2\%) e 25 a 34 anos (31,0\%). Não foram encontrados casos de menores de 18 anos até 10 anos, idade mínima considerada neste estudo.

A distribuição das ocorrências segundo tipo de acidente mostra que 300 (64,5\%) dos AT aconteceram em situação de deslocamento para o trabalho, casa ou refeição. Quanto à inserção da vítima no mercado de trabalho e referência à emissão de CAT, 
Tabela 1 Características das vítimas de acidentes de trabalho atendidas pelo SIATE* segundo sexo, idade, tipo de $\mathrm{AT}^{* *}$, mercado de trabalho, emissão da respectiva CAT ** , tipo de ocorrência e situação da vítima no acidente de trânsito; Londrina, PR, julho a dezembro de 2008

\begin{tabular}{|c|c|c|}
\hline Variável & $\mathrm{N}$ & $\%$ \\
\hline \multicolumn{3}{|l|}{ Sexo } \\
\hline Masculino & 363 & 78,1 \\
\hline Feminino & 102 & 21,9 \\
\hline \multicolumn{3}{|l|}{ Idade (anos) } \\
\hline $18-24$ & 150 & 32,2 \\
\hline $25-34$ & 144 & 31,0 \\
\hline $35-44$ & 85 & 18,3 \\
\hline $45-54$ & 60 & 12,9 \\
\hline $55-65$ & 26 & 5,6 \\
\hline \multicolumn{3}{|l|}{ Tipo de AT } \\
\hline Típico & 165 & 35,5 \\
\hline Trajeto & 300 & 64,5 \\
\hline \multicolumn{3}{|l|}{ Mercado de trabalho } \\
\hline Formal CLT & 300 & 64,5 \\
\hline Formal Estatutário & 16 & 3,5 \\
\hline Informal & 82 & 17,6 \\
\hline Autônomo & 67 & 14,4 \\
\hline \multicolumn{3}{|l|}{ Emissão da respectiva CAT } \\
\hline Sim & 178 & 38,3 \\
\hline Não & 168 & 36,1 \\
\hline Não, mas deveria & 119 & 25,6 \\
\hline \multicolumn{3}{|l|}{ Tipo de ocorrência } \\
\hline Acidente de trânsito & 376 & 80,9 \\
\hline Queda de nível elevado & 35 & 7,5 \\
\hline Acidente com máquina/queda de objeto sobre pessoa/queimadura & 29 & 6,2 \\
\hline Queda do mesmo nível & 14 & 3,0 \\
\hline Agressão & 11 & 2,4 \\
\hline \multicolumn{3}{|l|}{ Acidente de trânsito } \\
\hline Em moto & 305 & 81,1 \\
\hline Em bicicleta & 31 & 8,2 \\
\hline Em auto & 21 & 5,6 \\
\hline A pé & 14 & 3,7 \\
\hline Outro & 5 & 1,3 \\
\hline
\end{tabular}

*SIATE: Serviço Integrado de Atendimento ao Trauma em Emergência.

****AT: Acidente de trabalho.

粎: CAT: Comunicação de Acidente de Trabalho.

os achados mostram que a maioria das vítimas de AT (300 ou 64,5\%) está inserida no mercado formal de trabalho (CLT), portanto passível de emissão de CAT. No entanto, essas vítimas referiram emissão de CAT em 178 (38,3\%) casos. Apesar de busca cuidadosa, não foi encontrado registro de notificação SINAN para nenhum desses casos.

A distribuição dos AT segundo o tipo de ocorrência mostra que dos 465 AT, 376 (80,9\%) ocorrem no trânsito. Dos 376 acidentes de trânsito, 305 (81,1\%) envolveram motocicletas. As quedas de nível elevado aparecem em segundo lugar, totalizando 7,5\% dos casos.

As principais características dos AT envolvendo motociclistas no município de Londrina no período do estudo são mostradas na Tabela 2. O acidente envolvendo motociclista tem o seguinte perfil: dos 305 AT verificados, 240 (78,7\%) vítimas são 
Tabela 2 Características das vítimas de AT* envolvendo motocicletas, atendidas pelo SIATE**, segundo sexo, ocupação principal, mercado de trabalho, tipo de AT, emissão da respectiva CAT ** * , fraturas e óbitos; Londrina, PR, julho a dezembro de 2008

\begin{tabular}{|c|c|c|}
\hline Variável & $N$ & $\%$ \\
\hline \multicolumn{3}{|l|}{ Sexo } \\
\hline Masculino & 240 & 78,7 \\
\hline Feminino & 65 & 21,3 \\
\hline \multicolumn{3}{|l|}{ Ocupação principal } \\
\hline Motoboy/mototaxista/entregador & 50 & 16,4 \\
\hline Auxiliar administrativo & 28 & 9,2 \\
\hline Vendedor & 24 & 7,9 \\
\hline Atendente/auxiliar geral & 22 & 7,2 \\
\hline Serviços gerais & 17 & 5,6 \\
\hline Vigilante & 15 & 4,9 \\
\hline Pedreiro & 10 & 3,3 \\
\hline Outros & 139 & 45,6 \\
\hline \multicolumn{3}{|l|}{ Mercado de trabalho } \\
\hline Formal & 212 & 69,5 \\
\hline Informal & 46 & 15,1 \\
\hline Autônomo & 35 & 11,5 \\
\hline Estatutário & 12 & 3,9 \\
\hline \multicolumn{3}{|l|}{ Tipo de AT } \\
\hline Típico & 77 & 25,2 \\
\hline Trajeto & 228 & 74,8 \\
\hline \multicolumn{3}{|l|}{ Emissão da respectiva CAT } \\
\hline Sim & 128 & 42,0 \\
\hline Não & 95 & 31,1 \\
\hline Não, mas deveria & 82 & 26,9 \\
\hline \multicolumn{3}{|l|}{ Fratura } \\
\hline Em um segmento corporal & 131 & 43,0 \\
\hline Em dois segmentos corporais & 5 & 1,6 \\
\hline Sem fratura evidente no momento do resgate & 169 & 55,4 \\
\hline \multicolumn{3}{|l|}{ Óbito } \\
\hline Queda/colisão & 2 & 0,7 \\
\hline
\end{tabular}

*SIATE: Serviço Integrado de Atendimento ao Trauma em Emergência.

*AT: Acidente de trabalho.

**:*:*AT: Comunicação de Acidente de Trabalho.

do sexo masculino. A principal ocupação é de motoboy/mototaxista/entregador, com $50(16,4 \%)$ ocorrências; 212 (69,5\%) vítimas estão inseridas no mercado formal de trabalho. Ainda foram caracterizados $228(74,8 \%)$ acidentes de trajeto. A informação referida, afirmando a emissão da CAT ocorreu em $128(42,0 \%)$ casos. Contudo, 82 (26,9\%) deveriam ter sido notificados junto à Previdência Social e, segundo informação da vítima ou familiar, não o foram. Além disso, 95 (31,1\%) acidentes envolvendo motocicletas ocorreram com trabalhadores não segurados pelo SAT.

Houve politraumatismo envolvendo fratura evidente no momento do atendimento pelo SIATE em 136 (44,6\%) casos e óbito em dois casos.

\section{Discussão}

Os resultados revelam que o perfil das vítimas dos AT atendidos pelo SIATE é: jovens do sexo masculino, inseridos no mercado formal de trabalho e cujos acidentes ocorreram sobretudo no trânsito envolvendo motociclistas.

Dessa forma, não é por acaso que a interface entre acidentes de trabalho e de trânsito seja ressaltada neste estudo. No entanto, a proporção de $80 \%$ dos AT atendidos pelo SIATE envolvendo trânsito precisa ser depurada de influência das perdas de mais de $50 \%$ dos atendimentos mostradas no estudo.

Outra limitação que pode ser apontada neste estudo é a ausência de comparação entre a população 
de atendimentos SIATE estudada e a não estudada. O tratamento inicial dos dados acabou não permitindo sequer informar se os dados registrados nos RAS permitiriam esse tipo de abordagem. Estudos futuros devem adotar cuidados visando a realização desse tipo de comparação e também a contagem detalhada das eventuais perdas.

Os registros SIATE são manuscritos e armazenados no corpo de bombeiros, não tendo utilização posterior na forma de consolidação e nem análise por parte dos serviços de saúde. Essa forma de lidar com os dados facilita o extravio de relatórios SIATE, o que pode ser percebido com a perda de 29 RAS.

Destaca-se também como fator limitante a qualidade dos registros sobre identificação das vítimas nos relatórios dos hospitais, ora sem nenhuma informação quanto ao possível contato com a vítima ou familiar, ora com informações incorretas ou de difícil leitura. Essas ocorrências já foram relatadas em estudos que também mostram informações perdidas por campos não preenchidos ou preenchidos de forma ilegível como fator limitante para análise mais aprofundada (BINDER; WLUDARSKI; ALMEIDA, 2001; MEDEIROS et al., 2005; SPAGNUOLO; BALDO; GUERRINI, 2008).

Outro fato que merece destaque é o número de mortes violentas, 76 casos, constatados no local do acidente e encaminhados diretamente ao IML. A decisão de não abrir nova frente de busca de informações sobre a vítima e seus familiares a partir do IML limitou os achados deste estudo em relação à detecção de mortes possivelmente relacionadas ao trabalho nos atendimentos SIATE.

Nesse sentido, há fortes indicações de que a proporção de AT estimada neste estudo esteja aquém do que realmente poderia ter sido registrado, caso as limitações tivessem sido menores.

Quanto ao perfil das vítimas segundo sexo e idade, o achado tem sido atribuído à maior presença de homens na população exposta ao risco de acidentes e não a uma suposta maior acidentalidade ou propensão desse segmento a acidentes (MEDEIROS et al., 2005). Essa elevada proporção de jovens também pode ser explicada parcialmente pela participação dos motociclistas profissionais na clientela atendida pelo SIATE.

Achados semelhantes são relatados em estudo de amostra populacional realizado em Botucatu, SP, nos meses de junho e julho de 1997, que encontrou 82,9\% de população masculina, sendo $67,1 \%$ com idade entre 20 e 39 anos (BINDER; CORDEIRO, 2003). Em outro estudo, na análise das CATs no município de Piracicaba, SP, no ano de 2002, evidencia-se que $88,1 \%$ da população era do sexo masculino (MEDEIROS et al., 2005). Assim como estudo realizado em unidade de emergência de Salvador, BA, em que $90 \%$ dos AT ocorrem com trabalhadores do sexo masculino, com média de idade de 31 anos (CONCEIÇÃO et al., 2003).
No período estudado foram identificados 119 AT não captados pela Previdência Social no município, segundo informação da vítima ou familiar. As frequências relativas de acidentes captados neste estudo precisam ser analisadas considerando-se as perdas citadas de mais de $50 \%$ do universo de atendimentos, mas a captação via atendimentos SIATE de 168 (36,1\%) AT com trabalhadores inseridos em mercados de trabalho não regidos pela CLT sugere o potencial dessa fonte de informações. O fato de o estudo não explorar a proporção de casos do mercado formal que deixou de ser captada pelo sistema CAT, e de também não se checarem as possíveis irregularidades encobertas com a definição usada para autônomos nesse serviço reforçam a ideia de potencialidades do uso dessa fonte de informações.

Constatar a existência de vítimas de AT entre trabalhadores não cobertos pelo respectivo seguro pode representar estímulo ao desenvolvimento de ações de ST direcionadas a esses segmentos em consonância com o princípio de universalização da assistência. Neste estudo, nenhum dos 465 casos que, segundo informações das vítimas ou familiares, foram apontados como AT, foi notificado como tal no SINAN.

Não foram encontrados relatos assemelhados para comparação direta com os dados deste estudo. Todavia, em estudo que usa inquérito domiciliar no município de Botucatu, SP, cerca de um terço dos trabalhadores amostrados também não possuíam contrato formal de trabalho, mostrando a importância de identificar os AT nessa parcela da população (CORDEIRO et al., 2005).

Quanto ao tipo de ocorrência, a prática de informar à polícia e solicitar atendimento via SIATE ganha dimensões crescentes em acidentes ocorridos no espaço da rua. Waldvogel (2003), em estudo nos anos de 1997 a 1999, no estado de São Paulo, constata que metade das mortes decorrentes de AT típico ocorreu em via pública, indicando a transferência do local de trabalho para o espaço da rua. Esses achados sugerem que a violência urbana deva ser acrescida aos riscos identificados nos processos particulares a cada atividade profissional.

Outros estudos corroboram esses resultados, apontando o trânsito como causa relevante de AT (BARREIROS et al., 2003; SOUZA; PORTINHO; BARREIROS, 2006). Esse dado faz ressaltar a necessidade de mecanismos de prevenção de AT no espaço da rua e não apenas dentro da empresa.

Nesse contexto, quando se analisam os acidentes de trânsito estratificados por tipo de veículo, observa-se que, nos últimos anos, os acidentes de trânsito envolvendo motocicletas têm aumentado significativamente, pois tal veículo ganha cada vez mais a aceitação e aprovação da população, por ser ágil e de custo reduzido (OLIVEIRA; SOUSA, 2003; SANTOS et al., 2008). Ressalta-se ainda que o aumento do uso de motocicletas ocasiona maior exposição do usuário da moto nas vias públicas e pode trazer como consequência maior probabilidade 
de acidentes. Outros estudos corroboram esse achado (OLIVEIRA; SOUSA, 2006; SANTOS et al., 2008; SILVA; SOARES; ANDRADE, 2008).

Vê-se também que as ocupações de motoboy, mototaxista e entregador aparecem com maior número de vítimas, referendando a preocupação de outros autores com esses segmentos da sociedade (DINIZ; ASSUNÇÃO; LIMA, 2005; VERONESE; OLIVEIRA, 2006; SILVA; SOARES; ANDRADE, 2008).

Porém, a preocupação com uma categoria em especial não deve se sobrepor às análises das origens dos demais acidentes envolvendo motociclistas, independentemente de sua ocupação. Vale lembrar que grande parcela da população utiliza a moto como meio de transporte para o trabalho.

Na população de motociclistas abrangida neste estudo, 74,8\% dos atendimentos captados estavam no trajeto casa-trabalho-refeição. Estudo em Maringá, $\mathrm{PR}$, descreveu total de 28 vítimas que, no momento do acidente, estavam em atividades relacionadas ao trabalho, das quais nove (32,1\%) sofreram acidentes de trajeto e $19(67,8 \%)$ sofreram acidentes típicos (OLIVEIRA; SOUSA, 2006). A proporção de perdas descrita em nosso estudo precisa ser considerada como condição que influencia a diferença encontrada entre os percentuais de acidentes de trajeto deste estudo e do de Maringá, PR.

Além disso, a proporção de feridos nos acidentes de moto é maior do que naqueles dos demais veículos a motor; estima-se a proporção em cerca de 90\% para os acidentes de moto e 9\% para os demais veículos (BACCHIERI; BARROS, 2011).

Nos Estados Unidos, no período de 2001 a 2004, nos acidentes com motos, os ferimentos em extremidades ocorreram em 61,9\% dos pacientes; desses, 35,6\% foram fraturas (SANTOS et al., 2008).

O presente estudo encontrou quase $45 \%$ das vítimas de AT envolvendo motocicletas com fraturas em um ou mais segmentos corporais, o que comprova a vulnerabilidade da vítima face a esse tipo de agravo. Além de maior comprometimento do retorno à atividade produtiva, na maioria das vezes devido ao longo tempo de recuperação pós-acidente.

Estudo realizado em Rio Branco, AC, mostra que as pessoas que trabalham exibem razão de prevalência mais alta de acidentes de trânsito, o que se pode explicar pela exposição diária no percurso para o local de trabalho e vice-versa; relata ainda que os acidentes que aconteceram nesse trajeto foram categorizados como acidentes de trânsito (MAGALHÃES et al., 2011).

A escassez de literatura relatando a interface AT-acidente de trânsito pode contribuir para o fato de muitos AT não serem vistos como tais, sendo classificados em sistemas de informação ou mesmo em pesquisas científicas como acidentes de trânsito (GAWRYSZEWSKI; KOIZUMI; MELLO JORGE, 2004).

Entretanto, esses resultados sugerem a necessidade de se estabelecerem rotinas sistematizadas nos diversos serviços geradores de dados, como Unidades Básicas de Saúde, hospitais secundários, terciários, IML, serviços de urgência e emergência, em parceria com os serviços de vigilância à saúde, a fim de melhorar as intervenções de vigilância e organizar os demais serviços de saúde.

Sabe-se que no Brasil o dimensionamento real dos danos à saúde dos trabalhadores é prejudicado devido à subnotificação dos agravos e aos vieses dados aos fluxos oficiais de informação (GAWRYSZEWSKI; KOIZUMI; MELLO JORGE, 2004; REINHARDT; FISCHER, 2009).

Portanto, é imprescindível a notificação dos agravos em bancos de dados de interesse nacional, conforme preconiza o Ministério da Saúde (BRASIL, 2005b). Contudo, o tratamento das informações deve assumir claramente a lógica de sistemas de informação, revendo definições de casos, fluxos de informação, formas de consolidação e análise de dados, incentivo ao uso das informações em definições de prioridades, práticas de feedback para os alimentadores do sistema, entre outros.

Acreditamos que a publicação de estudos como este possa estimular o aumento de identificação e de notificação de AT fatais, assim como mostrar a importância da atuação conjunta da Vigilância Epidemiológica com a Vigilância Sanitária na área de Saúde do Trabalhador, para possibilitar análises dos AT notificados visando ações de prevenção e intervenção nos processos de trabalho de maior risco. Ademais, o estudo mostra que o SIATE é importante fonte de informação de acidentes de trabalho junto ao SUS - mesmo não lhe cabendo a notificação do caso, ele pode auxiliar na sua identificação e anotar a suspeita no RAS, cabendo ao hospital fazer a notificação na confirmação do caso.

Esses resultados podem indicar que os serviços de Saúde do Trabalhador precisam assumir um novo desafio: o da abertura de frente de trabalho pela prevenção de acidentes ocorridos no espaço da rua. Trata-se claramente de desafio a ser enfrentado em associação com outros organismos e instituições, em particular aqueles envolvidos com a segurança no trânsito.

Esses serviços precisam integrar esforços visando o reconhecimento dos aspectos relacionados à gestão do trabalho (por exemplo, manutenção de frota, horários de entregas, incentivos geradores de pressões de tempo, entre outros) que estão associados com a ocorrência de acidentes. Em particular, tanto para aqueles que envolvem o uso de motocicletas enquanto ferramenta de trabalho quanto para os que usam esses veículos como meio de transporte para ir ao e voltar do trabalho.

Recomenda-se a replicação deste estudo em outros cenários para se avaliar a visibilidade que tem sido atribuída às notificações de AT em serviços de saúde local. 


\section{Contribuições de autoria}

Baldo, R. C. S.: delineamento do projeto, coleta, análise e interpretação dos dados, elaboração do texto, revisão crítica e aprovação final. Spagnuolo, R. S.: elaboração do texto e revisão crítica. Almeida, I. M.: delineamento do projeto, análise e interpretação dos dados, revisão crítica e aprovação final.

\section{Referências}

BACCHIERI, G.; BARROS, A. J. D. Acidentes de trânsito no Brasil de 1998 a 2010: muitas mudanças e poucos resultados. Revista de Saúde Pública, São Paulo, v. 45, n. 5, p. 949-963, 2011. http://dx.doi. org/10.1590/S0034-89102011005000069.

BARREIROS, M. F. et al. Mortalidade por causas externas relacionadas ao trabalho: investigação de matérias jornalísticas da Bahia: saúde do trabalhador na Bahia: construindo a informação. Cadernos de Saúde do Trabalhador, Salvador, v. 1, p. 44-47, 2003.

BINDER, M. C. P.; CORDEIRO, R. Sub-registro de acidentes do trabalho em localidade do Estado de São Paulo, 1997. Revista de Saúde Pública, São Paulo, v. 37, n. 4, p. 409-416, 2003. http://dx.doi.org/10.1590/ S0034-89102003000400004.

BINDER, M. C. P.; WLUDARSKI, S. L.; ALMEIDA, I. M. Estudo da evolução dos acidentes do trabalho registrados pela Previdência Social no período de 1995 a 1999, em Botucatu, São Paulo. Cadernos de Saúde Pública, Rio de Janeiro, v. 17, n. 4, p. 915-924, 2001. http://dx.doi.org/10.1590/S0102311X2001000400025.

BRASIL. Ministério da Saúde. Portaria ${ }^{\circ} 777$, de 28 de abril de 2004. Dispõe sobre os procedimentos técnicos para a notificação compulsória de agravos à saúde do trabalhador em rede de serviços sentinela específica, no Sistema Único de Saúde - SUS. In: BRASIL. Ministério da Saúde. Departamento de Ações Programáticas Estratégicas. Legislação em saúde: caderno de legislação em saúde do trabalhador. 2. ed. Brasília, 2005a.

. Ministério da Saúde. Portaria ${ }^{\circ}$ 3908, de 30 de outubro de 1998. Estabelece procedimentos para orientar e instrumentalizar as ações e serviços de saúde do trabalhador no Sistema Único de Saúde. In: BRASIL. Ministério da Saúde. Departamento de Ações Programáticas Estratégicas. Legislação em saúde: caderno de legislação em saúde do trabalhador. 2. ed. Brasília, 2005b.

. Ministério da Saúde. Secretaria de Atenção à Saúde. Departamento de Ações Programáticas Estratégicas. Notificação de acidentes de trabalho fatais, graves e com crianças e adolescentes. Brasília, 2006.

. Ministério da Saúde. Portaria ${ }^{0}$ 104, de 25 de janeiro de 2011. Define as terminologias adotadas em legislação nacional, a relação de doenças, agravos e eventos em saúde pública de notificação compulsória em todo o território nacional e estabelece fluxo, critérios, responsabilidades e atribuições aos profissionais e serviços de saúde. Diário Oficial da União, Brasília, DF, 26 jan. 2011.

. Ministério da Previdência Social. Instituto Nacional do Seguro Social, Empresa de Tecnologia e Informações da Previdência Social. Anuário estatístico da previdência social. Brasília, 2013.

. Ministério da Saúde. Portaria $\mathrm{n}^{\circ}$ 1271, de 6 de junho de 2014. Define a Lista Nacional de Notificação Compulsória de doenças, agravos e eventos de saúde pública nos serviços de saúde públicos e privados em todo o território nacional. Diário Oficial da União, Brasília, DF, 9 jun. 2014. Disponível em: $<$ dtr2004.saude.gov.br/sinanweb/novo/Documentos/ Portaria_1271_06jun2014.pdf >. Acesso em: 21 jul. 2014.

. Ministério da Previdência Social. Estatística de acidentes do trabalho 2013. Brasília. Disponível em: <http://www.previdencia.gov.br/dados-abertos/ aeat-2013/estatisticas-de-acidentes-do-trabalho-2013/ subsecao-d-acidentes-do-trabalho-segundo-omunicipio/tabelas-d-2013/> . Acesso em: 28 set. 2015.

\section{CENTERS FOR DISEASE CONTROL AND}

PREVENTION - CDC. EpiInfo, versão 3.3.2. Atlanta, 2005. Disponível em: < https://wwwn.cdc.gov/epiinfo/ html/prevVersion.htm>. Acesso em: 28 set. 2015.

CONCEIÇÃO, P. S. A. et al. Acidentes de trabalho atendidos em serviço de emergência. Cadernos de Saúde Pública, Rio de Janeiro, v. 19, n. 1, p. 111-117, 2003. http://dx.doi.org/10.1590/S0102311X2003000100012.

CORDEIRO, R. et al. Subnotificação de acidentes do trabalho não fatais em Botucatu, SP, 2002. Revista de Saúde Pública, São Paulo, v. 39, n. 2, p. 254-260, 2005. http://dx.doi.org/10.1590/S0034-89102005000200017.

DINIZ, E. P. H.; ASSUNÇÃO, A. A.; LIMA, F. P. A. Prevenção de acidentes: o reconhecimento das estratégias operatórias dos motociclistas profissionais como base para a negociação de acordo coletivo. Ciência e Saúde Coletiva, Rio de Janeiro, v. 10, n. 4, p. 905-916, 2005. http://dx.doi.org/10.1590/S141381232005000400014 .

FACCHINI, L. A. et al. Sistema de informação em saúde do trabalhador: desafios e perspectivas para 
o SUS. Ciência e Saúde Coletiva, Rio de Janeiro, v. 10, n. 4, p. 857-867, 2005. http://dx.doi.org/10.1590/ S1413-81232005000400010.

GAWRYSZEWSKI, V. P.; KOIZUMI, M. S.; MELLO JORGE, M. H. P. As causas externas no Brasil no ano 2000: comparando a mortalidade e a morbidade. Cadernos de Saúde Pública, Rio de Janeiro, v. 20, n. 4, p. 995-1003, 2004. http://dx.doi.org/10.1590/S0102311X2004000400014.

INSTITUTO BRASILEIRO DE GEOGRAFIA E ESTATÍSTICA - IBGE. População economicamente ativa. Brasília. Disponível em: < http://www.ibge. gov.br/home/estatistica/populacao/condicaodevida/ indicadoresminimos/conceitos.shtm > . Acesso em: 2 nov. 2014.

MAGALHÃES, A. F. et al. Prevalência de acidentes de trânsito auto-referidos em Rio Branco, Acre. Revista de Saúde Pública, São Paulo, v. 45, n. 4, p. 738-744, 2011. http://dx.doi.org/10.1590/S0034-89102011005000031.

MEDEIROS, M. A. T. et al. Acidentes de trabalho em Piracicaba em 2002. Saúde em Revista, Piracicaba, v. 7, n. 15, p. 7-13, 2005.

MELLO JORGE, M. H. P.; KOIZUMI, M. S. Gastos governamentais do SUS com internações hospitalares por causas externas: análise no Estado de São Paulo, 2000. Revista Brasileira de Epidemiologia, São Paulo, v. 7, n. 2, p. 228-238, 2004.

OLIVEIRA, N. L. B.; SOUSA, R. M. C. Diagnóstico de lesões e qualidade de vida de motociclistas, vítimas de acidentes de trânsito. Revista Latino-Americana de Enfermagem, Ribeirão Preto, v. 11, n. 6, p. 749-756, 2003.

. Retorno à atividade produtiva de motociclistas vítimas de acidentes de trânsito. Acta Paulista de Enfermagem, São Paulo, v. 19, n. 3, p. 284-289, 2006. http://dx.doi.org/10.1590/S0103-21002006000300005.

ORGANIZAÇÃO MUNDIAL DE SAÚDE - OMS. Relatório mundial sobre violência e saúde OMS.
Tradução Secretaria de Estado dos Direitos Humanos do Ministério da Justiça. Genebra, 2002.

REINHARDT, E. L.; FISCHER, F. M. Barreiras às intervenções relacionadas à saúde do trabalhador do setor saúde no Brasil. Revista Panamericana de Salud Pública, Washington, v. 25, n. 5, p. 411-417, 2009. http://dx.doi.org/10.1590/S1020-49892009000500005.

SANTOS, A. M. R. et al. Perfil das vítimas de trauma por acidente de moto atendidas em um serviço público de emergência. Cadernos de Saúde Pública, Rio de Janeiro, v. 24, n. 8, p. 1927-1938, 2008.

SILVA, D. W.; SOARES, D. A.; ANDRADE, S. M. Atuação profissional de motoboys e fatores associados à ocorrência de acidentes de trânsito em Londrina-PR. Epidemiologia e Serviços de Saúde, Brasília, v. 17, n. 2, p. 135-137, 2008.

SOUZA, N. S. S.; PORTINHO, B. G.; BARREIROS, A. F. Acidentes de trabalho com óbito registrados em jornais no Estado da Bahia. Revista Baiana de Saúde Pública, Salvador, v. 30, n. 1, p. 77-89, 2006.

SPAGNUOLO, R. S.; BALDO, R. C. S.; GUERRINI, I. A. Análise epidemiológica dos acidentes com material biológico registrados no Centro de Referência em Saúde do Trabalhador - Londrina-PR. Revista Brasileira de Epidemiologia, São Paulo, v. 11, n. 2, p. 315-323, 2008. http://dx.doi.org/10.1590/S1415790X2008000200013.

VERONESE, A. M.; OLIVEIRA, D. L. L. C. Os riscos dos acidentes de trânsito na perspectiva dos motoboys: subsídios para a promoção da saúde. Cadernos de Saúde Pública, Rio de Janeiro, v. 22, n. 12, p. 2717-2721, 2006. http://dx.doi.org/10.1590/ S0102-311X2006001200021.

WALDVOGEL, B. C. A população trabalhadora e os acidentes do trabalho fatais. São Paulo em Perspectiva, São Paulo, v. 17, n. 2, p. 42-53, 2003. http://dx.doi. org/10.1590/S0102-88392003000200006. 